\title{
EFEITO DE AMBIENTE SOBRE A PRODUTIVIDADE DE FEIJÃO CARIOCA PARA O ESTADO DE SANTA CATARINA $\left({ }^{1}\right)$
}

\author{
FABIANI DA ROCHA $\left({ }^{2}\right)$; DIEGO TOALDO $\left({ }^{2}\right)$; LEIRI DAIANE BARILI $\left({ }^{2}\right)$; NAINE MARTINS DO VALE $\left({ }^{2}\right)$; \\ SORAYA GARCIA $\left({ }^{2}\right)$; JEFFERSON LUÍS MEIRELLES COIMBRA $\left({ }^{2 *}\right)$; GILCIMAR ADRIANO VOGT $\left({ }^{3}\right)$; \\ ALTAMIR FREDERICO GUIDOLIN $\left({ }^{2}\right)$
}

\begin{abstract}
RESUMO
Quinze genótipos de feijão (Phaseolus vulgaris L.) foram caracterizados quanto à adaptabilidade e estabilidade de rendimento de grãos em cinco ambientes, para cada época de semeadura (safra e safrinha), em 2006 e 2007. Foram empregados os métodos de Eberhart e Russel (1966) e Wricke e Weber (1986). Os resultados indicaram a ocorrência de forte interação genótipo x ambiente, com reflexos em apenas quatro genótipos de feijão com baixa estabilidade de rendimento de grãos quando cultivados no período recomendado para cultura (safra), principalmente em conseqüência dos valores significativos dos desvios da regressão observados. Com base nos resultados, é possível indicar os genótipos CHC 97-29 (safra), FAM 03 e CHC 97-15 (safrinha) para cultivo na Região Sul do Brasil, uma vez que houve alto rendimento de grãos e insensibilidade a alterações de ambiente. Para cultivo na safra, FAM 03 deve ser recomendado aos agricultores altamente tecnificados, pois é responsivo significativamente às melhorias de ambiente quando cultivados na época recomendada para cultura.
\end{abstract}

Palavras-chave: Phaseolus vulgaris L., previsibilidade, interação genótipo x ambiente.

\section{ABSTRACT \\ ENVIRONMENTAL EFFECTS ON YIELD OF CARIOCA BEAN IN SANTA CATARINA STATE}

Fifteen common bean genotypes (Phaseolus vulgaris L.) were evaluated as to adaptability and stability of grain yield in five environments for crop season and late crop season, during 2006 and 2007. Adaptability and stability were estimate by Eberhart and Russell (1966) and by Wricke e Weber (1986) methods. The results indicated a strong genotype $x$ environment interaction, for four genotypes that presented in crop season, due to significant deviations of regression values. Due to high grain yield and insensitivity to environment changes the genotypes CHC 97-29 is indicated in crop season, FAM 03 and CHC 97-15 in late crop season for southern region of Brazil. FAM 03 responds significantly to good conditions in environment in recommend growing season and should be recommended to be cultivated with modern technologies.

Key words: Phaseolus vulgaris L., predictability, genotype x environment interaction.

$\left({ }^{1}\right)$ Recebido para publicação em 6 de maio de 2008 e aceito em 20 de março de 2009.

$\left(^{2}\right)$ Universidade do Estado de Santa Catarina (UDESC), Departamento de Agronomia, Programa de Pós-Graduação em Ciências Agrárias, Instituto de Melhoramento e Genética Molecular da UDESC (IMEGEM). Av. Luiz de Camões, 2090, Bairro Conta Dinheiro, 88520-000 Lages (SC). E-mail: coimbrajefferson@cav.udesc.br ${ }^{*}$ ) Autor correspondente.

$\left({ }^{3}\right)$ Epagri - Centro de Pesquisa para Agricultura Familiar, Caixa Postal, 791, 89801-970 Chapecó (SC), Brasil. 


\section{INTRODUÇÃO}

O feijão (Phaseolus vulgaris L.) é um dos mais importantes constituintes da dieta do brasileiro, por ser notavelmente uma excelente fonte proteica. O Brasil é considerado o maior produtor e consumidor mundial de feijão. A cultura do feijão é considerada entre os produtos agrícolas o de maior importância econômico-social (VIEIRA et al., 2005).

No Estado de Santa Catarina a cultura do feijão é cultivada sob diferentes condições de solo e de clima e tal fato causa uma influência significativa da interação genótipo $\mathrm{x}$ ambiente no rendimento de grãos (ELIAS et al., 1999). Este componente pode tornar onerosa e lenta a seleção de genótipos com características promissoras (CARVAlHo et al., 2002). Dessa forma deve ser avaliada a interação do genótipo perante os ambientes ( $\mathrm{G} \times \mathrm{A})$, incrementando assim a correlação linear entre o fenótipo e o genótipo, permitindo a recomendação de genótipos mais produtivos e adaptados à Santa Catarina. Para a obtenção de informações pormenorizadas sobre o comportamento de cada genótipo diante das variações de ambiente devem ser realizadas análises de adaptabilidade (resposta de um genótipo às modificações do ambiente) e estabilidade (previsibilidade do genótipo em função de estímulos ambientais). Através do conhecimento da adaptabilidade e da estabilidade é possível a identificação de cultivares de comportamento previsível e responsivo.

Para a análise da adaptabilidade e estabilidade de um grupo de genótipos testados em uma série de ambientes há mais de uma dezena de metodologias e dentre elas destacamos Finlay e WiILKINSON (1963); EBERHART e RUSSEL (1966); TAI (1971); Verma et al. (1978); Wricke (1965); Wricke e Weber (1986). As metodologias mais utilizadas são a de EBERHART e RUSSEL (1966) baseada em regressão e a de WricKe e Weber (1986), em análise de variância.
Assim, este trabalho tem como objetivo estimar e avaliar os parâmetros de adaptabilidade e estabilidade para quinze genótipos de feijão carioca cultivados em cinco ambientes (na safra e na safrinha).

\section{MATERIAL E MÉTODOS}

Foram utilizados dados de rendimento de grãos $\left(\mathrm{kg} \mathrm{ha}^{-1}\right)$ provenientes do Ensaio Estadual de Linhagens e Cultivares de feijão ou Ensaio de Valor de Cultivo e Uso, coordenados pela EPAGRI (Centro de Pesquisa para Agricultura Familiar). Os ensaios foram desenvolvidos na safra e na safrinha de 2006 e 2007, em diferentes ambientes do Estado de Santa Catarina: Águas de Chapecó (safrinha), Campos Novos (safra), Canoinhas (safra), Chapecó (safrinha e safra), Ituporanga (safrinha), Lages (safra), Ponte Serrada (safra), Urussanga (safrinha) e Xanxerê (safrinha). Nesses ambientes houve contrastes para clima e altitude (Tabela 1). Foram utilizados 15 genótipos de feijão carioca: BRS Horizonte, Carioca, CHC 97-15, CHC 97-29, CHC 98-27, CHC 98-51, CHC 98-61, FAM 03, FT Bonito, FT Magnífico, IPR Juriti, IPR Saracura, LP 99-79, Pérola, SCS 202 Guará.

A semeadura foi realizada na época indicada pelo zoneamento agroclimático para o Estado de Santa Catarina. O preparo do solo, a adubação e a calagem foram efetuadas conforme recomendado pelo manual de adubação e calagem (RolAs, 2004). Os tratos culturais foram efetuados sempre que necessários. Os ensaios foram instalados em blocos ao acaso, com quatro repetições e a unidade experimental foi composta por quatro linhas de $4 \mathrm{~m}$ de comprimento, espaçadas de 0,45 metros. A densidade de semeadura foi de 15 sementes viáveis por metro linear. A área útil da parcela foi de $3,6 \mathrm{~m}^{2}$. A variável avaliada foi rendimento de grãos a $13 \%$ de umidade.

Tabela 1. Caracterização dos locais onde foram conduzidos os ensaios de Valor de Cultivo e Uso (VCU) na safra e safrinha, no Estado de Santa Catarina. Lages, SC, 2008

\begin{tabular}{llcc}
\hline Local & Clima & Temperatura média anual & Altitude \\
\hline & & ${ }^{\circ} \mathrm{C}$ & $\mathrm{m}$ \\
Águas de Chapecó (safrinha) & Mesotérmico úmido & 20 & 291 \\
Campos Novos (safra) & Temperado & $15-25$ & 947 \\
Canoinhas (safra) & Temperado c.f.b. & $15-25$ & 839 \\
Chapecó (safra e safrinha) & Temperado & $15-25$ & 670 \\
Ituporanga (safrinha) & Subtropical c.f.a & 17 & 370 \\
Lages (safra) & Subtropical CS'a & 16 & 916 \\
Ponte Serrada (safra) & Mesotérmico úmido & 16 & 1067 \\
Urussanga (safrinha) & Subtropical & $15-25$ & 49 \\
Xanxerê (safrinha) & Mesotérmico úmido & $18-30$ & 800 \\
\hline
\end{tabular}


Utilizou-se o software SAS 9.1.3 (SAS, 2007) para análise das estimativas dos quadrados médios das análises de variância, para o rendimento de grão, pelo teste $\mathrm{F}$, a $5 \%$ de probabilidade de erro. Os parâmetros de estabilidade e adaptabilidade foram analisados de acordo com a metodologia de EBERHART e RUSSEL (1966) através do software Genes (CRUZ, 2001) o qual adota o seguinte modelo de regressão linear: $Y_{i j}=\mu_{i}+\beta_{i} I_{j}+S_{d i}^{2}$. Sendo: $Y_{i j}=$ média da cultivar $i$ ambiente $j ; \mu_{i}=$ média da cultivar $i$ em todos os ambientes; $\beta_{i}=$ coeficiente de regressão; $I_{j}=$ índice de ambiente; $S^{2}{ }_{d i}=$ desvio da regressão, mais o erro experimental contido em $Y_{i j}$ A metodologia proposta por estes autores é baseada na análise de regressão, e quanto à adaptabilidade classificam-se em: a) genótipos com adaptabilidade geral ou ampla: são aqueles com $\beta_{i}$ igual a $1 ; \mathrm{b}$ ) genótipos com adaptabilidade específica a ambientes favoráveis: são aqueles com $\beta_{i}$ maior que $1 ;$ c) genótipos com adaptabilidade específica a ambientes desfavoráveis: são aqueles com $\beta_{i}$ menor que 1. Quanto à estabilidade, foram avaliados pelos componentes da variância atribuídos aos desvios de regressão $\left(S_{d i}^{2}\right)$, e considerados: a) genótipos estáveis: aqueles com $S^{2}{ }_{d i}$ igual a $0 ;$ b) genótipos instáveis: aqueles com $S^{2}{ }_{d i}$ diferentes de 0 ; ambos submetidos à análise de significância pelo teste $F$.

Foi realizada, ainda, a avaliação da estabilidade por meio do método proposto por WRICKE e Weber (1986). Este é um dos procedimentos mais empregados pelos melhoristas europeus, sobretudo pela facilidade de interpretação (SouzA et al., 2006). O parâmetro de estabilidade proposto por este método é denominado de "ecovalência", estimado decompondo a soma de quadrados da interação genótipos $\mathrm{x}$ ambientes nas partes devidas a genótipos isolados (CRUZ e REGAZZI, 2004), através da seguinte equação: $W_{i}^{2}=\Sigma_{\mathrm{j}}^{\mathrm{n}=1}\left(Y_{i j}-Y_{i-} Y_{j}+Y_{. .}\right)^{2}$ em que: $W_{i}^{2}$ é a ecovalência; $Y_{i j}$ é a média da cultivar $i$ no ambiente $j$; $Y_{i}$ é a média da cultivar $i ; Y_{. j}$ é a média do ambiente j; e Y.. é a média geral. De acordo com esta metodologia são considerados genótipos mais instáveis aqueles com $W_{\mathrm{i}}$ (ecovalência) maior.

\section{RESULTADOS E DISCUSSÃO}

Os coeficientes de variação observados foram 12,24 e $11,88 \%$ para safra e safrinha respectivamente, e podem ser classificados como médios (PimentelGomes e Garcia, 2002), dando confiabilidade aos resultados, permitindo assim, que se prossiga com a análise dos dados obtidos (Tabela 2).

Pode-se observar que os resultados das análises de variância tanto para a safra como para a safrinha revelaram efeitos significativos $(p<0,05)$ de genótipos, locais e da interação genótipo $\mathrm{x}$ ambiente (Tabela 2). A estimativa do quadrado médio do local revela que as diferenças entre ambientes foram maiores que os demais fatores experimentais. Tal resultado concorda com o constatado pelos autores CoImBRA et al. (1999), que também obtiveram magnitude elevada para o quadrado médio do ambiente, trabalhando com 21 genótipos de feijão carioca em três ambientes. A presença da interação genótipo $x$ ambiente indica que os genótipos tiveram resposta diferenciada aos locais. Esse resultado é semelhante ao analisado pelos autores RANE et al. (2007) que, avaliando 25 genótipos de trigo em 18 locais, constataram forte influência do ambiente sobre o valor do fenótipo. Esse fato pode refletir a sensibilidade dos genótipos, de acordo com as condições de cultivo verificadas em todas as regiões agrícolas do Brasil.

Tabela 2. Análise de variância para a variável rendimento de grãos $\left(\mathrm{kg} \mathrm{ha}^{-1}\right)$ de 15 genótipos de feijão do grupo carioca, cultivados em cinco ambientes na safra (Canoinhas, Chapecó, Lages, Ponte Serrada, Campos Novos) e na safrinha (Águas de Chapecó, Chapecó, Ituporanga, Urrussanga, Xanxerê), sendo F.V as fontes de variação, Gl os graus de liberdade e QM o quadrado médio.

\begin{tabular}{lccccc}
\hline \multirow{2}{*}{ Fonte de Variação } & \multicolumn{2}{c}{ Safra } & & \multicolumn{2}{c}{ Safrinha } \\
\cline { 2 - 3 } \cline { 5 - 6 } & GL & QM & & GL & 381841,2 \\
\hline Bloco & 3 & 321866,9 & 3 & $535193,4^{*}$ \\
Genótipo (G) & 14 & $526979,8^{*}$ & & 14 & $22232191,5^{*}$ \\
Local (L) & 4 & $81144648,6^{*}$ & & 4 & $91946,5^{*}$ \\
G x L & 56 & $351788,1^{*}$ & & 56 & 116837,9 \\
Erro & 222 & 189390,2 & & 221 & - \\
\hline Total & 299 & - & 298 & 11,88 \\
CV (\%) & - & 12,24 & - & \\
\hline
\end{tabular}

* Significativo a $5 \%$ de probabilidade de erro pelo teste F. 
Assim, pode ser notada a importância da avaliação da adaptabilidade e da estabilidade, a fim de observar genótipos com comportamento previsível e que sejam responsivos aos diferentes ambientes, em condições especificas ou amplas, para que a partir desta caracterização possam ser feitas recomendações com maior critério científico (Elias et al., 2005).

Quanto aos rendimentos médios de grãos, os genótipos foram separados em três grupos: superior (S), médio (M) e inferior (I). Na safra, observou-se apenas no genótipo CHC 97-29 desenvolvimento superior aos demais genótipos avaliados; seus rendimentos médios variaram de 3.290 a $3.845 \mathrm{~kg} \mathrm{ha}^{-1}$ com média geral de $3.555 \mathrm{~kg} \mathrm{ha}^{-1}$. Para a safrinha, o desenvolvimento dos genótipos FAM 03 e CHC 97-15 foi superior aos demais; quanto ao rendimento, a variação foi de 2.535 a 3.103 e a média geral, de 2.875 $\mathrm{kg} \mathrm{ha}^{-1}$ (Tabela 3).

O método proposto por Eberhart e Russel considera simultaneamente a produtividade, estabilidade e a adaptabilidade a ambientes gerais, favoráveis e desfavoráveis, e dessa forma deve ser o preferido dentre os demais métodos (CARGNELUTTI-FILHO et al., 2007). Assim, pode ser inferido que os genótipos FAM 03 e LP 99-79 quando cultivados na safra tiveram significância quanto à adaptabilidade, sendo o primeiro adaptado a ambientes favoráveis (seu rendimento aumenta $19 \mathrm{~kg} \mathrm{ha}^{-1}$ para cada $100 \mathrm{~kg} \mathrm{ha}^{-1}$ devido à melhoria das condições de ambiente) e o segundo genótipo adaptado a ambientes desfavoráveis. Na avaliação do parâmetro estabilidade, nos genótipos BRS Horizonte, CHC 9715, CHC 98-51 e CHC 98-61 observa-se desvio de regressão $\left(\mathrm{S}_{\mathrm{d}}^{2}\right)$ diferente de 0 , indicando que esses genótipos são imprevisíveis, ou seja, não pode ser predito seu comportamento nos ambientes testados. Para os demais genótipos, não houve significância para os parâmetros adaptabilidade e estabilidade, constatando-se que esses genótipos possuem adaptabilidade ampla e seu comportamento é previsível, dentro dos ambientes avaliados. Assim, de acordo com os rendimentos, o genótipo a ser recomendado é CHC 97-29 que possui rendimento superior (S) (Tabela 3).

Por outro lado, todos os genótipos cultivados na safrinha tiveram adaptabilidade ampla $(\beta=1)$, excetuando o genótipo SCS 202 Guará que revelou adaptabilidade a ambientes desfavoráveis $(\beta<1)$. Esse genótipo pode ser vantajoso para os pequenos agricultores que não têm condições de garantir um ambiente ideal para a cultura. $\mathrm{N}$ parâmetro estabilidade não houve significância para nenhum dos genótipos avaliados; por esse motivo, permite-se afirmar que todos os genótipos avaliados tiveram comportamento previsível e podem ser recomendados a todos os ambientes avaliados sem que haja variação na produtividade estimada. Assim, para a safrinha é recomendado o CHC 97-15 e FAM 03 que são estáveis, possuem adaptabilidade ampla e as maiores médias (3091 e $3103 \mathrm{~kg} \mathrm{ha}^{-1}$ respectivamente) (Tabela 3).

Pode-se observar na tabela 3, que tanto na safra como na safrinha os genótipos com adaptabilidade geral foram os mesmos que tiveram as maiores médias de rendimento, também constatado em genótipos avaliados por Elias et al. (2007). O fato de todos os genótipos serem responsivos de maneira estável pode ser decorrente de que a safra 2006/2007 foi favorecida em termos de precipitação pluvial, com chuvas bem distribuídas contribuindo para o excelente rendimento da maioria dos genótipos. Diferentemente de outras safras de avaliações cujos genótipos não foram bem supridos em termos de precipitação pluvial, fazendo com que fossem responsivos de maneira relativamente diferenciada um do outro.

Deste modo pode-se notar que o genótipo ideal para cultivo na safra não é o mesmo para a safrinha, uma vez que o genótipo desejado é aquele com maior rendimento médio, adaptabilidade ampla $(\beta=1)$ e desvio de regressão igual a zero $\left(\mathrm{S}_{\mathrm{d}}=0\right)$. $\mathrm{O}$ desempenho diferenciado dos genótipos na safra e safrinha comprova a influência do ambiente sobre o genótipo, e a importância de se cultivar genótipos que sejam recomendadas às condições de cultivo de cada região. Dessa forma, para cultivo em safra, o genótipo a ser recomendado seria o CHC 97-29, pois possui a maior média, adaptabilidade ampla e previsibilidade. Já para a safrinha seria o FAM 03 e CHC 97-15.

Segundo o modelo de Wricke e Weber (1986), o genótipo mais estável é aquele com menor estimativa para a ecovalência, ou seja, o genótipo com menor contribuição para a interação genótipo $x$ ambiente. Ordenando-se os valores de ecovalência ( $\mathrm{Wi} \%)$, de forma decrescente tem-se então: a) Safra: LP 99-79, BRS Horizonte, CHC 9861, CHC 98-51, CHC 97-15, FAM 03, IPR Saracura, FT Magnífico, Pérola, CHC 98-27, IPR Juriti, CHC 97-29, FT Bonito, SCS 202 Guará e Carioca. De acordo com este método, o genótipo de maior contribuição para a interação genótipo ambiente foi LP 99-79, seguido do BRS Horizonte com rendimento inferior (I) aos demais. O genótipo com a menor contribuição foi Carioca, o qual seria passível de cultivo nos ambientes avaliados, com rendimento médio (M); b) Safrinha: CHC 98-27, CHC 98-51, SCS 202 Guará, Carioca, FAM 03, IPR Saracura, BRS Horizonte, FT Magnífico, CHC 9715, IPR Jurití, CHC 97-29, LP 99-79, FT Bonito, CHC 98-61 e Pérola. 


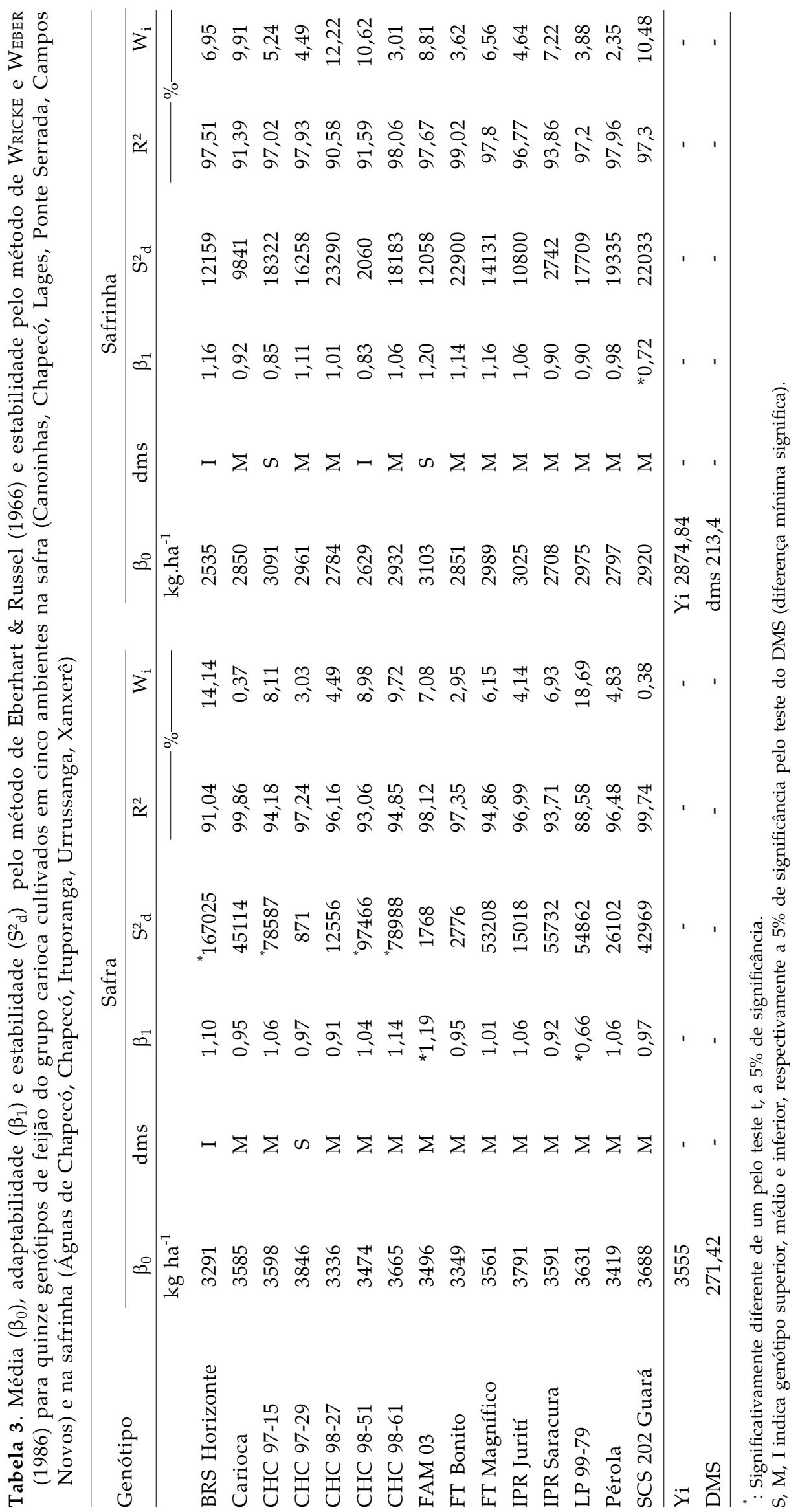


O comportamento dos genótipos na safrinha, portanto, não foi análogo à safra, ou seja, responderam de forma diferente à época de plantio. Os genótipos com maior contribuição para o efeito da interação genótipo x ambiente foram CHC 98-27 e CHC 98-51 com rendimento médio $(\mathrm{M})$ e inferior (I) respectivamente. A cultivar Pérola foi a de menor contribuição e, portanto, o genótipo mais estável com rendimento médio (M) (Tabela 3 ).

Os resultados sobre estabilidade são semelhantes em ambos os métodos, de modo que os genótipos cultivados na safra considerados instáveis pelo modelo de EBERHART e RUSSEL (1966) são também aqueles com altos valores de ecovalência. A correlação entre os métodos é de 0,89 , o que indica alta concordância entre os métodos e justifica os resultados semelhantes (LópEz et al., 2007).

De acordo com os resultados, pode-se perceber a importância do estudo da adaptabilidade e estabilidade, pois os genótipos que foram instáveis em geral possuem rendimento médio $(\mathrm{M})$ ou inferior (I), em comparação com os genótipos estáveis. Constata-se que a exploração da interação genótipo $\mathrm{x}$ ambiente, bem como o entendimento dos fatores que as compõem, mediante o uso de metodologias, tem fundamental importância para a recomendação de genótipos. Se o melhorista tem conhecimento do comportamento do genótipo perante as mudanças do ambiente é possível ter maior confiabilidade na escolha de genótipos amplamente ou especificamente adaptados (Grüneberg et al., 2005).

Desse modo, sabe-se que a interação genótipo $x$ ambiente tem merecido atenção especial de melhoristas de plantas, pois a mesma restringe o progresso da seleção. É sabido que estabilidade de produção e a adaptabilidade a ambientes são características herdáveis e estimáveis por métodos estatísticos, tais características tornam-se passíveis de melhoramento (Piana et al., 1999). Portanto, a identificação de cultivares de maior estabilidade fenotípica é de suma importância, a fim de reduzir o efeito da interação genótipo $x$ ambiente e possibilitar a recomendação de cultivares com maior segurança (Elias et al., 2005).

\section{CONCLUSÕES}

1. O desenvolvimento dos genótipos é contrastante, quando cultivados em diferentes épocas de semeadura.

2. Na safrinha, somente o genótipo SCS 202 Guará adapta-se a ambientes desfavoráveis.
3. Os genótipos CHC 97-29 (safra), FAM 03 e CHC 97-15 (safrinha) associam alto rendimento de grão com adaptabilidade ampla e estabilidade elevada

\section{AGRADECIMENTOS}

Os autores agradecem ao CNPq, à CAPES, à UDESC e à FAPESC pelo apoio financeiro no desenvolvimento deste trabalho.

\section{REFERÊNCIAS}

CARVALHO, C.G.P.; ARIAS, C.A.A.;TOLEDO, J.F.F.; ALMEIDA, L.A.; KIIHL, R.A.S.; OLIVEIRA, M.F.O. Interação genótipo $x$ ambiente no desempenho produtivo da soja no Paraná. Pesquisa Agropecuária Brasileira, v.37, p.989-1000, 2002.

CARGNELUTTI-FILHO, A.;PERECIN, D.;MALHAREIROS, E.B.; GUADAGNIN, J.P. Comparação de Métodos de Adaptabilidade e Estabilidade Relacionados à Produtividade de Grãos de Cultivares de Milho. Bragantia, v.66, p.571-578, 2007.

COIMBRA, J.L.M.; CARVALHO, F.I.F.; HEMP, S.; SILVA, S.A. Adaptabilidade e estabilidade fenotípica em genótipos de feijão de cor (Phaseolus vulgaris L.) em três ambientes distintos. Ciência Rural, v.29, p.441-448, 1999.

CRUZ, C.D. Programa Genes-versão Windows: aplicativo computacional em genética e estatística. Viçosa. Universidade Federal de Viçosa. 2001.

CRUZ, C.D.; REGAZZI, A.J.; CARNEIRO, P.C.S. Modelos biométricos aplicados ao melhoramento genético. 3. ed. Viçosa: UFV, 2004. 480p.

EBERHART, S.A.; RUSSEL, W.A. Stability parameters for comparing varieties. Crop Science, v.6, p.36-40, 1966.

ELIAS, H.T.;HEMP, S.;CANTON, T. Análise da interação genótipo $x$ ambiente na avaliação de cultivares de feijão em Santa Catarina. Pesquisa Agropecuária Gaúcha, v.5, p.271-275, 1999.

ELIAS, H.T.;SILMAR, H.;SCAPIM, C.A.; RODOVALHO, M.A.; ROYER, M.R.; MORA, F.; BARRETO, R.R. Análise da estabilidade de genótipos de feijoeiro no Estado de Santa Catarina. Acta Scientiarum Agronomy, v.27, p.623-628, 2005.

ELIAS, H.T.; BACKES, R.L.; VIDIGAL, M.C.G.;BALBINOT, JR., A. A.; HEMP, S.Estabilidade e adaptabilidade de linhagens e cultivares de Feijão do grupo carioca. Scientia Agraria, v.8, p.379-384, 2007.

FINLAY, K.W.; WILKINSON, G.N. The analysis of adaptationin a plant breeding programme. Astralian Journal Agricultural Research, East Melbourne, v.14, p.742-54, 1963.

GRÜNEBERG, J.W.; MANRIQUE' K.; Zhang, D.; HERMANN, M. Genotype x Environment Interactions for a Diverse Set of Sweetpotato Clones Evaluated across Varying Ecogeographic Conditions in Peru. Crop Science, v.45, p.2160-2171, 2005. 
LÓPEZ, P.J.D.; GARCÍA, L.M.V.; CASTELLANOS, J.S. Estabilidad del rendimiento de genotipos de papa (Solanum tuberosum L.). Fitotecnia Mexicana, v.30, p.279-284, 2007.

PIANA, C.F.B.; ANTUNES, I.F.; SILVA, J.G.C.; SILVEIRA, E.P. Adaptabilidade e estabilidade do rendimento de grãos de genótipos de feijão. Pesquisa Agropecuária Brasileira, v.34, p.553-564, 1999.

PIMENTEL-GOMES, F.; GARCIA, C.H. Estatísticas aplicada a experimentos agronômicos e florestais: exposição com exemplos e orientações pra uso de aplicativos. Piracicaba: FEALQ, 2002.309p.

RANE, J.; PANNU, K.R.; SOHU, V.S.; SAINI, R.S.; MISHRA, B.; SHORAN, J.; CROSSA, J.; VARGAS, M. JOSHI, A.K. Performance of yield and stability of advanced wheat genotypes under heat stress environments of the indogangetic plains. Crop Science, v.47, p.1561-1573, 2007.

ROLAS-Rede oficial de laboratórios de análise de solo e de tecido vegetal. Manual de adubação e calagem para os estados do Rio Grande do Sul e Santa Catarina. 10.ed. Porto Alegre: Sociedade Brasileira de Ciência do Solo, 2004. 400p.

SAS Institute Inc. SAS 9.1.3 (TS1M3) for windows microsoft. Cary, NC, SAS Institute, 2007.

SOUZA, A.A.; FREIE, E.C.; BRUNO, R.L.A.; CARVALHO, L.P.; FILHO, J L.S.; PEREIRA, W. E. Estabilidade e adaptabilidade do algodoeiro herbáceo no Cerrado do Mato Grosso e Mato Grosso do Sul. Pesquisa Agropecuária Brasileira, v.41, n.7, 2006.

TAI, G.C.C. Genotype stability analysis and its application to potato regional trials. Crop Science, v.11, p.184-190, 1971.

VERMA, M.M.; CHAHAL, G.S.; MURTY, B.R. Limitations of conventional regression analysis: a proposed modification. Theoretical and Applied Genetics, v.53, p.89-91, 1978.

VIEIRA, C.; BORÉM, A.; RAMALHO, M.A.P.;CARNEIRO, J.E.S. Melhoramento de Feijão. In BORÉM, A. Melhoramento de Plantas Cultivadas. 2.ed. Viçosa: UFV, 2005. p.301-391.

WRICKE, G. Zur berechüng der okovalenz bei sommerweizen und hafer. Zeitschrisft fuer Pflanzezuchtung, v.52, p.127-138, 1965.

WRICKE, G. WEBER, E.W. Quantitative genetics and selection in plant breeding. Berlin: Walter de Gruyter, 1986. 406p. 